\title{
Perdagangan Internasional Dan Ham: Relasinya Dengan Sustainable Development
}

\author{
Satria Unggul Wicaksana Prakasa \\ Fakultas Hukum Universitas Muhammadiyah Surabaya \\ Jl. Raya Sutorejo No.59, Dukuh Sutorejo, Mulyorejo, Kota Surabaya, Jawa Timur 60113, \\ (031) 3811966/satria@fh.um-surabaya.ac.id
}

\begin{abstract}
Industrialization and export and import activities between countries around the world in this era of globalization. the issue of sustainable development in which the trade also related with physical and environmental aspects, but also considers the benefits and security of the man himself. Many facts encountered that some cases were found, the non-compliance of transnational corporations to pay attention to the principles of human rights fulfillment. Legal issues raised: (1) provisions on international trade, environment, and human rights. (2) case analysis related to international trade, environment and human rights. The research method used statue approach, conceptual approach, and case approach. Research results: (1) Countries are expected an important role in securing how the effects of human rights violations resulting from international trade activities can be minimized in such a way through the principles to protect, and respect for the human rights of citizens. Thus, the public benefits from many international trade activities conducted by the state. as well as sustainable development is also realized through the principle of remedy for transnational corporations found to have done environmental damage and accompanied by human rights violations in its business activities. (2) In the cases presented, it has proved that transnational corporations directly commit human rights violations and environmental destruction, to threats to the state sovereignty process. This issue needs to be addressed in the enforcement of international legal mechanisms. In the extraterritorial court's decision, it is difficult for plaintiffs who are victims of justice and accountability for human rights violations and environmental damage.
\end{abstract}

Keywords: International Trade; Sustainable Development; Human Rights, International Law Enforcement

\begin{abstract}
Abstrak
Industrialisasi dan kegiatan ekspor dan impor antar negara di seluruh dunia merupakan suatu keharusan di era globalisasi ini. persoalan sustainable development di mana perdagangan juga perhatikan aspek fisik dan lingkungan, namun juga memperhatikan manfaat dan keamanan dari manusia itu sendiri, banyak fakta yang ditemui bahwa beberapa kasus ditemukan, adanya ketidakpatuhan dari korporasi transnasional untuk memperhatikan prinsip-prinsip pemenuhan HAM. Isu hukum yang diangkat: 1) ketentuan-ketentuan mengenai perdagangan internasional, lingkungan, dan HAM? 2) analisis kasus terkait perdagangan internasional, lingkungan dan HAM? Metode penelitian yang digunakan statue approach, conceptual approach, dan cases approach. Hasil penelitian: 1) Negara diharapkan mempunyai peran andil penting dalam hal menjamin bagaimana efek pelanggaran HAM yang diakibatkan oleh aktivitas
\end{abstract}


perdagangan internasional dapat diminimalisir sedemikian rupa melalui prinsip perlindungan (to protect), dan penghormatan (to respect) HAM warga negara. Sehingga, masyarakat mendapatkan banyak manfaat dari aktivitas perdagangan internasional yang dilakukan oleh negara. serta pembangunan berkelanjutan juga terwujud melalui prinsip memperbaiki (to remedy) bagi korporasi transnasional yang ditemukan telah melakukan kerusakan lingkungan dan disertai pelanggaran HAM dalam aktivitas bisnisnya; 2) Pada kasus-kasus yang telah disajikan telah membuktikan bahwa korporasi transnasional secara langsung melakukan pelanggaran HAM dan perusakan lingkungan, hingga ancaman (threat) terhadap proses kedaulatan negara. Persoalan ini perlu diatasi dalam penegakkan mekanisme hukum internasional. Pada putusan pengadilan ekstrateritorial tersebut, sukar bagi penggugat yang merupakan korban mendapatkan keadilan dan pertanggungjawaban atas pelanggaran HAM dan kerusakan lingkungan yang ditimbulkan.

Kata Kunci: Perdagangan Internasional; Sustainable Development; HAM; Penegakkan Hukum Internasional

\section{A. PENDAHULUAN}

Industrialisasi dan kegiatan ekspor dan impor antar negara di seluruh dunia merupakan suatu keharusan di era globalisasi ini, bagaimana kepentingan profit oriented menjadi tujuan utama dengan mengesampingkan aspek-aspek lain yang sebenarnya berimplikasi lebih besar dalam kehidupan manusia. Salah satu dari fungsi perdagangan internasional adalah menciptakan kesejahteraan sosial umat manusia, itu artinya bahwa ada misi sosial dari diterapkannya sistem perdagangan internasional itu sendiri (Rao, 2000: 3).

Jika kita menilik agenda perdagangan internasional, hal yang perlu diperhatikan adalah bahwa pasca Uruguay Round 1994 yang ditandai dengan established organisasi perdagangan internasional (World Trade Organization (WTO)) di mana hal tersebut menjadikan batasan-batasan perjanjian internasional dalam hal perdagangan telah dirubah secara radikal sehingga prinsip kedaulatan yang diakui dalam perjanjian Westphalia dulu mulai bergeser. Itu semua berganti dengan standar-standar yang dibuat WTO yang notabene negara-negara dengan hasrat penguasaan atas perdagangan internasional dengan menutup akses untuk menciptakan keadilan dan demokratisasi perdagangan internasional atau secara keras dapat dikatakan regulasi ini hanya sekedar monopoli dari negara maju dengan didukung analisis dari ilmuwan, politisi, dan pelaku usaha, prinsip musyawarah negara-negara anggota tidak seberapa penting untuk diperhatikan.

Sebaliknya, terjadinya penghapusan segala border and barrier baik bersifat tariff maupun non-tariff yang dituangkan dalam klausula perdagangan internasional semakin menunjukkan bahwa ada kepentingan liberalisasi pasar yang coba dilegitimasi oleh WTO, dan hal ini mendapat respon ketidakpuasan dari masyarakat internasional karena perdagangan internasional telah membawa efek perubahan 
substantif dan mengesampingkan aspek Hak Asasi Manusia (HAM) (Francioni, 2001: 3-4).

Segala aspek yang berkenaan dengan perdagangan seyogyanya juga memperhatikan aspek pembangunan berkelanjutan (sustainable development). Artinya. tidak hanya kepentingan ekonomi liberal saja yang menjadi kunci dalam melakukan perdagangan internasional, namun persoalan kemanusiaan dan kesetaraan harus pula diperhatikan. Fakta yang terjadi adalah seringnya negara maju menjadikan negara berkembang sebagai basis produksi perdagangan internasional melalui sistem korporasi transnasional, namun tidak memperhatikan perlindungan HAM dan pembangunan berkelanjutan. Hal inilah yang menjadi perhatian dari masyarakat internasional, untuk membuat regulasi perdagangan internasional yang seimbang (Pelaez, 2005: 39-40).

Persoalan sustainable development di mana perdagangan juga perhatikan aspek fisik dan lingkungan, namun juga memperhatikan manfaat dan keamanan dari manusia itu sendiri. Banyak fakta yang ditemui bahwa baik trans national corporate/multi national corporate (TNC/MNC) yang selanjutnya disebut korporasi transnasional, tidak melakukan kegiatan perdagangannya dengan perspektif HAM, seperti hak buruh yang tidak dapat terpenuhi, perampasan hak-hak masyarakat adat (indigeneous people), kelaparan, banjir, asap akibat pembakaran hutan untuk alih fungsi lahan, dan berbagai macam persoalan hukum yang ditimbulkan (Fasterling, dan Demuijnck , 2013: 820).

Penerapan norma hukum internasional sangat penting dilaksanakan di era globalisasi ini, khususnya hubungan antara perdagangan, lingkungan hidup, dan HAM, maka perlu ada analisis terkait persoalan tersebut. Melihat fakta-fakta dan latar belakang di atas, maka isu hukum yang diangkat dalam artikel ini adalah:

1. Bagaimanakah Ketentuan-ketentuan mengenai perdagangan internasional, lingkungan, dan HAM

2. Bagaimanakah analisis kasus terkait perdagangan internasional, lingkungan dan HAM.

\section{B. METODE PENELITIAN}

Metode penelitian dalam artikel ini untuk mengetahui keterkaitan perdagangan internasional, persoalan lingkungan, dan kaitannya dengan pemenuhan HAM dengan menggunakan pendekatan statute approach. Suatu pendekatan dalam penelitian hukum sebagai suatu proses menemukan aturan hukum, prinsip-prinsip hukum secara doktrinal guna menjawab isu hukum yang sedang diangkat. Pendekatan ini beranjak dari regulasi hukum baik dalam aspek hukum internasional maupun hukum nasional baik bersifat vertikal maupun horizontal, untuk mengkaji aturan hukum yang sejajar atau yang bersifat hierarkis. (Marzuki, 2005: 96-101). 
Melalui pendekatan konseptual (conceptual approach) dan pendekatan kasus (case approach) dengan melakukan analisis terkait kompatibelitas antara praktikpraktik perdagangan internasional dengan prinsip-prinsip HAM dan lingkungan internasional berdasarkan doktrin dan pandangan para ahli serta pandangan konseptual dan teoritis, hal ini bertujuan untuk memecahkan isu hukum yang diajukan tidak hanya dengan pendekatan perundang-undangan semata yang bersifat terbatas (Marzuki, 2005: 137-140). Sehingga, penulis dapat menguraikan secara komprehensif dan ideal keterkaitan antara perdagangan internasional dan HAM serta relasinnya dengan misi pembangunan berkelanjutan.

\section{PEMBAHASAN DAN ANALISIS}

1. Ketentuan-Ketentuan Mengenai Perdagangan Internasional, HAM, dan Pembangunan Berkelanjutan

\section{a. Definisi dan Ruang Lingkup Perdagangan Internasional}

Definisi perdagangan berdasarkan ketentuan Business Dictionary adalah (http://www.businessdictionary.com/definition/international-trade.html, akses 3 Januari 2018):

"the exchange of goods and services along international borders. This type of trade allows for a greater competition and more competitive pricing in the market. The competition results in more affordable products for the consumer. The exchange of goods also affects the economy of the wordl as dictated by supply and demand, making goods and services obstainable which may not otherwise be avalilable to consumers globally."

Dapat dimaksudkan di sini bahwa perdagangan internasional adalah perdagangan lintas batas untuk tujuan menciptakan harga barang dan jasa yang kompetitif.

Teori tentang perdagangan ini terkenal dan diperkenalkan oleh ekonom terkemuka Adam Smith, yang membuat teori yang disebut sebagai absolute advantage theory. Smith memandang bahwa kecenderungan perdagangan internasional adalah sama dengan perdagangan pada umumnya (adanya barter, pertukaran, dan lain-lain). Sebaliknya, di setiap perdagangan jelas kepentingan pribadi telah dicari oleh masing-masing pedagang, karena hal tersebut yang menjadi motif dari perdagangan internasional, namun bukan hanya pelaku usaha yang mendapatkan keuntungan, tetapi juga bisa dimanfaatkan secara keseluruhan dalam perdagangan internasional (Schumacher, 2012: 57).

Bahwa demi mencapai keuntungan yang sempurna, pelaku usaha dapat memaksimalkan pembagian kerja dengan tujuan peningkatan kuantitas dengan identifikasi-identifikasi alasan pengembang ini, yaitu: (1) peningkatan ketangkasan dalam pekerjaan tertentu; (2) pengghematan waktu produksi dan pekerjaan; dan (3) penemuan mesin-mesin baru yang memfasilitasi dan membatasi tenaga kerja dan memungkinkan menghasilkan produksi yang banyak. Hal ini akan berimbas pada pendapatan yang lebih baik, dan efek besarnya adalah menciptakan pertumbuhan ekonomi negara dengan pesat (Schumacher, 2012: 58-59). 
Mengapa perdagangan internasional memberi keuntungan yang besar pula pada negara-negara lainnya, menurut Adam Smith, hal ini terjadi karena (Schumacher, 2012: 59):

".....it gives a value to their superfluities, by exchanging them for something else, which may satisfy a part of their wants, and increase their enjoyments. By means of it the narrowness of the home market does not hinder the division of labour in any particular branch of art or manufacture from being carried to the highest perfection. By opening a more extensive market for whatever part of the produce of their labour may exceed the home consumption, it encourages them to improve its productive powers, and to augment its annual produce to the utmost, and thereby to increase the real revenue and wealth of the society."

Maka di sinilah yang penting dalam teori Adam Smith, bahwa adanya perdagangan internasional juga menciptakan pasar yang lebih luas. Melalui dukungan dari kekuatan pekerja dan produksi yang maksimal, diharapkan agar negara-negara dapat merasakan "kesenangan" dari diterapakannya perdagangan internasional. Namun, pernyataan Adam Smith memunculkan kontroversi dengan memberi poin, bahwa dalam perdagangan internasional bagi penduduknya dapat barter dengan barang yang menghasilkan keuntungan di dalam negeri, dengan cara ini kebutuhan pendidik masyarakat dapat terpenuhi. Dan konsep yang terakhir adalah bagaimana menciptakan harga yang sama melalui aturan yang selaras antara perdagangan domestik dan perdagangan internasional, hal ini agar menjamin keadilan dan persaingan usaha (competitiveness) dalam praktik perdagangan (Schumacher, 2012: 59-62).

Pembagian kerja dapat dilakukan dengan baik dan dibarengi dengan kondisi pasar domestik yang setara dengan pasar internasional serta keuntungan yang didapatkan akibat perdagangan internasional dilakukan secara maksimal karena pasar internasional sangat banyak, maka hal tersebut sudah termasuk esensi yang paling ideal dalam perdagangan internasional menurut Adam Smith.

\section{b. Definisi dan Ruang Lingkup Lingkungan Hidup}

Secara geografis, lingkungan merupakan wilayah yang cukup terbatas termasuk atmosphere dan stratosphere. Pengertian lain dapat ditemukan bahwa: (Anton and Shelton, 2011: 2-4).

"Environment: a complex of natural and anthropogenic factors and elements that are mutually interrelated and affect the ecological equilibrium and the quality of life, human health, the cultural and historical heritage and the landscape.

Pada Convention on Civil Liability for Damage Resulting from Activities Dangerous to the Environment Pasal 2 Ayat (1) mengartikan lingkungan sebagai: "The sum of all external conditions affecting the life, development and survival of an 
organism" (Anton and Shelton, 2011: 2-4). Memberikan pengertian dan batasan di dalam ketentuan mengenai lingkungan bertujuan untuk memberikan perlindungan hukum sampai pada taraf sejauh mana konvensi internasional maupun ketentuan hukum nasional dapat mencakupnya, selain itu dapat pula menuntut tanggung jawab (responsibilty) maupun tanggung gugat (liabilty) bagi pelaku perusakan lingkungan. Dengan kompleksitas dari pengertian mengenai lingkungan tersebut diharapkan memberi kejelasan mengenai sistem hukum manakah yang dapat diaplikasikan dan diterapkan dalam penyelesaian persoalan khususnya terkait dengan pelanggar lingkungan hidup.

\section{c. Definisi dan Ruang Lingkup HAM}

Definisi mengenai HAM sebenarnya tidak ada norma yang kaku yang mengartikan sebagai satu tafsir pengertian tentang makna HAM, namun menurut United Nation Human Right Office of the Hight Commision mendefinisikan HAM sebagai (http://www.ohchr.org/EN/Issues/Pages/WhatareHumanRights.aspx, diakses pada 1 Januari 2018):

"Human rights are rights inherent to all human beings, whatever our nationality, place of residence, sex, national or ethnic origin, colour, religion, language, or any other status. We are all equally entitled to our human rights without discrimination. These rights are all interrelated, interdependent and indivisible"

Ketentuan-ketentuan mengenai HAM diatur dan tersebar ke dalam beberapa norma HAM universal, seperti hak Sipil Politik (SIPOL) dan hak Ekonomi, Sosial, dan Budaya (EKOSOB) serta berbagai macam konvensi turunan dari dua "generasi HAM" tersebut hingga dapat diratifikasi dan diterapkan bagi Negara-negara di seluruh dunia. Artinya, pesan HAM adalah pesan universal untuk menciptakan rasa kemanusiaan yang berkeadilan dan diharapkan dapat dijiwai lalu ditaati oleh seluruh umat manusia di muka bumi.

Terkait dengan HAM yang berkenaan dengan lingkungan dapat kita temukan definisinya di dalam Report of the U.N. Conference on the Human Environment, Declaration of the U.N. Conference on the Human Environment, U.N. Doc. A/CONF.48/14/Rev.1, p. 3 (June 5-16, 1972) (Anton and Shelton, 2011: 118):

"man has the fundamental right to freedom, equality and adequate conditions of life, in an environment of a quality that permits a life of dignity and well-being, and he bears a solemn responsibility to protect and improve the environment for present and future generations"

Bahwa nilai dari norma hukum tersebut dalam pemanfaatan kekayaan lingkungan ditujukan untuk menciptakan kualitas lingkungan yang lebih baik dengan keadaan apapun secara berkeadilan dan bertanggungjawab, sehingga prinsip pembangunan yang berkelanjutan akan terwujud walaupun dalam konteks ini kegiatan industrialisasi dan perdagangan internasional terus bergerak secara masif, namun dari kegiatan tersebut dapat berdimensi pembangunan yang berkelanjutan dan menghindari praktik-praktik pelanggaran HAM. 


\section{d. Business \& Human Rights Principles: a Guideline Principles}

Penegakan hukum internasional mengenai HAM dan suistanable development dalam aspek perdagangan internasional telah diatur dalam beberapa konvensi internasional, ketentuan Pasal XX GATT 1994 menjadi prinsip perdagangan internasional yang perlu berisikan:

General Exceptions

Subject to the requirement that such measures are not applied in a manner which would constitute a means of arbitrary or unjustifiable discrimination between countries where the same conditions prevail, or a disguised restriction on international trade, nothing in this Agreement shall be construed to prevent the adoption or enforcement by any contracting party of measures:

(a) necessary to protect public morals;

(b) necessary to protect human, animal or plant life or health;

(c) relating to the importations or exportations of gold or silver;

(d) necessary to secure compliance with laws or regulations which are not inconsistent with the provisions of this Agreement, including those

Dalam ketentuan Pasal XX GATT 1994 tersebut jelas memberikan petunjuk, bahwa negara peserta perdagangan internasional wajib memenuhi ketentuan barang-barang yang diperkenankan menjadi komoditas perdagangan. Ketentuan tersebut wajib dituangkan di dalam regulasi hukum nasional, khususnya berkaitan dengan komoditas yang diperlukan untuk menjaga moral publik, menjaga manusia, hewan, ataupun lingkungan hidup, untuk kegiatan impor dan ekspor emas dan perak, serta untuk memastikan bahwa produk yang diperdagangkan oleh negara peserta WTO tidak bertentangan dengan regulasi hukum nasional negara peserta.

Proses perdagangan internasional tidak lepas dari proses investasi dan pendirian perusahaan di negara tempat basis produksi berada (host country). Mekanisme hukum internasional telah mengatur perdagangan dan kaitannya dengan cara-cara investasi (Trade Related Investment Measures (TRIMs)). TRIMs ditujukan oleh WTO untuk membuat negara-negara anggota tidak melakukan diskriminasi atas produk/dan atau tenaga kerja asing yang melanggar prinsip national treatment. TRIMs juga melarang tindakan investasi yang mengakibatkan terlanggarnya prinsip-prinsip perdagangan yang telah diatur oleh WTO. Ini menunjukkan bahwa dalam hubungan perdagangan internasional yang dilakukan antara korporasi transnasional dengan host country wajib saling menghargai dan dilarang saling mendiskriminasi, agar kemudian antara kedua belah pihak terwujud relasi perdagangan yang saling menguntungkan, tanpa melanggar prinsip-prinsip perdagangan internasional yang telah ditentukan oleh WTO/GATT (WTO, 2015: 51).

Selain prinsip yang tertera di dalam WTO, Perserikatan Bangsa-Bangsa (PBB) sebagai induk dari semua organisasi internasional telah merancang prinsip-prinsip dasar dalam penyelenggaraan kegiatan bisnis tanpa meninggalkan kewajiban 
pemenuhan HAM bagi korporasi tersebut, prinsip-prinsip tersebut dituangkan di dalam Norms on the Responsibilities of Transnational Corporations and Other Business Enterprises with Regard to Human Rights. (U.N. Doc. E/CN.4/Sub.2/2003/12/Rev.2 (2003)):

"States have the primary responsibility to promote, secure the fulfilment of, respect, ensure respect of and protect human rights recognized in international as well as national law, including ensuring that transnational corporations and other business enterprises respect human rights. Within their respective spheres of activity and influence, transnational corporations and other business enterprises have the obligation to promote, secure the fulfilment of, respect, ensure respect of and protect human rights recognized in international as well as national law, including the rights and interests of indigenous peoples and other vulnerable groups."

dijelaskan dalam Pasal 1 UN Norm Principles di atas, bahwa negara penandatangan prinsip tersebut mempunyai kewajiban untuk melindungi kepentingan, penghormatan, tanggung jawab, dan pemenuhan HAM warga negaranya dari berbagai macam aktivitas bisnis yang dilakukan korporasi transnasional (https://business-humanrights.org/en/united-nations-sub-commission-norms-onbusiness-human-rights-explanatory-materials, akses pada 10 Januari 2018).

UN Norms tersebut mengatur berbagai macam komponen dan tidak hanya bagi korporasi transnasional, juga kepada pekerja korporasi transnasional, penghormatan terhadap kedaulatan negara bagi korporasi transnasional yang menjalankan bisnisnya di negara yang bersangkutan, perlindungan hak-hak konsumen, hingga wajibnya melindungi lingkungan dan mengantisipasi dampak destruktif yang potensi ditimbulkan oleh korporasi transnasional. Dapat dikatakan bahwa UN Norms tersebut bertujuan sebagai prinsip dasar dan standar global dalam pencegahan konflik di negara tempat korporasi internasional berkegiatan, serta meningkatkan kepercayaan masyarakat terhadap korporasi internasional tersebut, (Prihandono dan Khairunisa, 2016: 63), sehingga tidak ada denial (penolakan) terhadap pengoperasian koorpasi transnasional karena terjadinya hubungan yang adil dan dalam kegiatan bisnisnya.

Untuk mengukur sejauh mana suatu negara beserta pihak-pihak terkait dalam kaitannya terhadap kegiatan bisnis yang dilakukan oleh korporasi transnasional serta pemenuhan HAM dan perlindungan lingkungan. UN Norms tersebut dianggap tidak dapat memenuhi ekspektasi negara tempat di mana korporasi transnasional tersebut beroperasi, khususnya berkaitan dengan prinsip-prinsip yang mengikat dan terukur (binding and measurable principles) berkenaan dengan bisnis dan HAM. Maka dari itu, PBB membuat UN Guiding Principles on Business and Human Rights (UNGP) melalui Resolusi Dewan HAM PBB Nomor 17/4, ditandatangani pada 16 Juni 2011 (UN Office of the High Commision for Human Right, 2014: 8).

UNGP mengatur terkait prinsip-prinsip bisnis dan HAM dan relasinya terkait dengan lingkungan dengan merumuskan tiga (3) prinsip yang dikenal, yaitu: protect, 
respect, and remidy (UN Office of the High Commision for Human Right, 2014: 8-9). Prinsip-prinsip tersebut dituangkan dalam kerangka kerja yang diinginkan oleh PBB melalui: 1) Kewajiban negara untuk melindungi (protect) hal-hal yang bertentangan dengan prinsip-prinsip HAM yang ada termasuk yang dilakukan oleh pelaku bisnis dan dituangkan dalam kebijakan yang berkaitan; 2) tanggung jawab korporasi yang harus dilakukan untuk tindakan dan ketentuan yang seharusnya (due diligence) berkaitan dengan upaya menghindari dan mencegah dampak yang dilakukan, salah satunya berkaitan dengan pelanggaran HAM yang mungkin dilakukan oleh korporasi transnasnasional tersebut, sehingga hak-hak masyarakat, pekerja, dan pihak-pihak terkait merasakan dampak penghormatan (respect) atas tindakan yang mungkin ditimbulkan oleh korporasi transnasional dalam kegiatan bisnisnya; dan 3) Pemenuhan kebutuhan untuk akses yang optimal dalam penyelesaian persoalan yang dialami oleh korban berkenaan dengan perbuatan korporasi yang berhubungan dengan kegiatan bisnis baik secara mekanisme yudisial maupun mekanisme non-yudisial, khususnya dalam hal pemulihan (remedy) akibat dampak kegiatan usaha tersebut, di mana ketika korporasi transnasional tersebut mendirikan perusahaannya di suatu negara, maka sifat yurisdiksinya tidak hanya di kantor pusat perusahaan tersebut (home country), namun pemberlakukan yurisdiksinya ekstra-teritorial. Sehingga, negara yang terdampak atas operasi bisnis dan kegiatan perdagangan internasional tersebut termasuk dalam kaitannya dengan kerusakan lingkungan, akan meminta pertanggungjawaban pemulihan dan penjatuhan hukuman bagi korporasi transnasional yang melanggar (UN Office of the High Commision for Human Right, 2014: 8-65).

Selain sistem perdagangan internasional dan HAM yang dihasilkan melalui PBB dan WTO, negara-negara yang mempunyai kepentingan untuk investasi internasional dan korporasi multinasional tergabung di dalam organisasi internasional, yaitu Organization for Economic Cooperation \& Developmend (OECD). OECD membuat guideline untuk investasi oleh korporasi multinasional yang disahkan pada 2011 dengan nama "OECD Guideline for Multinational Enterprises 2011" yang kemudian disebut OECD Guideline. OECD Guideline bersifat sukarela (voluntary) dan tidak mengikat (non-binding) bagi negara anggota, sehingga dalam penegakannya tergantung pada itikad baik negara anggota.

OECD Guiedline terdiri atas: konsep dan prinsip investasi internasional yang dilakukan korporasi multinasional; kebijakan; keterbukaan; perlindungan HAM; ketenagakerjaan dan hubungan industrial; lingkungan; larangan suap; kepentingan konsumen; Ipteks; persaingan usaha; perpajakan. Untuk melaksanakan prinsipprinsip pada OECD Guideline, diharuskan untuk membentuk National Contract Point (NCP) sebagai forum diskusi berkaitan dengan pelaksanaan OECD Guideline, serta menjadi "penyambung" kepentingan warga negara host country yang terkena dampak pelanggaran HAM dari kegiatan korporasi transnasional dan 
menyampaikkannya didalam forum internasional (Prihandono dan Khairunnisa, 2016: 98-99).

\section{e. Sustainable Development}

Upaya masyarakat internasional dalam mendukung terciptanya perdagangan internasional yang sustainable dan berwawasan HAM sesuai dengan ketentuan WTO telah dibuat komite khusus untuk menangani kasus-kasus perdagangan dan lingkungan yang diberi nama Commitee Trade and Environment (CTE) yang memiliki tugas-tugas yang cukup spesifik, seperti ulasan yang dilakukan oleh Franseco Francioni (2001: 147) berikut:

"The creation of the Committee on Trade and Environment (CTE) within the framework of the World Trade Organisation (WTO) is possibly the best illustration of this trend. sAs is known, the CTE was entrusted with the specific task of recommending appropriate rules to improve the interaction between trade and environment with a view to promoting sustainable development. The wide array of issues addressed by the CTE include the interrelationship between the multilateral trade system, on the one hand, and Multilateral Environmental Agreements (MEAs) and/or national environmental policies and national trade measures enacted for environmental purposes on the other. Moreover, the CTE is intended to tackle the problems of the export of domestically prohibited goods, the effect of environmental measures on market access, the issue of transparency of national environmental measures, the compatibility of national standards and technical regulation with the international trading regime as well as the relation between the dispute settlement provisions of the WTO and the other dispute settlement mechanisms provided by MEAs"

Salah satu institusi beserta instrumen hukum internasional, yang bertugas menjaga limbah dan emisi yang ditimbulkan dari pelaksanaan perdagangan internsional, yaitu Environment Justice (EJ) Framework. Melalui serangkaian kegiatan monitoring dan assasement untuk menciptakan pertumbuhan ekonomi yang berkeadilan dan memperhatikan aspek sustainable development. Tujuan dibentuknya EJ adalah membuat kerangka kerja dan strategi untuk mengeliminasi ketidakadilan negara terhadap persoalan lingkungan, juga EJ juga dituntut untuk membuat kerangka kerja bagi negara peserta untuk membuat kebijakan dan model penanggulangan kerusakan lingkungan, karena kerusakan lingkungan akan berakibat terhadap gangguan kesejahteraan masyarakat negara anggota. (Chioma, 2009: 20).

Norma hukum internasional telah dibuat terkait konsep environment dan human right, tepatnya dalam The Stockholm Declaration on Human Environment 1972 yang berisikan tentang bagaimana kesadaran masyarakat internasional untuk menciptakan kondisi lingkungan hidup berkualitas dalam aspek pembangunan yang berkelanjutan, karena dibalik kondisi lingkungan hidup yang sehat di sana dimungkinkan adanya pemenuhan, perlindungan dan penegakkan HAM itu sendiri (http://www.unisosdem.org/article detail.php?aid=6343\&coid=1\& caid=56\&gid=3, akses pada 24 Januari 2018). 
Pada tahun 1983, General Assembly PBB membuat komite yang menangani persoalan lingkungan dan pembangunan berkelanjutan yang diberi nama The World Commission on Environment and Development atau lebih dikenal Butland Commission. Di dalam laporannya, Butland Commission memaparkan tentang Sustainable development sebagai:

"sustainable development as development that meets present and future environment and development objectives and concluded that without an equitable sharing of the costs and benefits of environmental protection within and between countries, neither social justice nor sustainable development can be achieved"

Sehingga, di dalam pelaksanaan United Nation Environment Program (UNEP), di Rio de Jainero, isu-isu tentang perdagangan dan aspek kemanusiaan dibawa kepada konvensi tersebut. Lima di antaranya diusulkan untuk dibahas dan menjadi konvensi-konvensi internasional turunan, yaitu: The U.N. Framework Convention on Climate Change and the Convention on Biological Diversity. Konferensi ini juga membahas mengenai konvensi-konvensi yang secara judul cukup sulit untuk ditempuh, yaitu: "Non-legally binding authoritative statement of principles for a global consensus on the management, conservation and sustainable development of all types of forests (Anton and Shelton, 2011: 72-75).

Jika kita merujuk hasil dari konvensi Rio De Janeiro 1992, ada beberapa prinsip-prinsip tentang pembangunan berkelanjutan yang dibangun di dalam konvensi tersebut yang berisikan tentang 27 prinsip pokok yang disuarakan masyarakat internasional, yaitu: (Report of the United Nations Conference on Environment and Development A/CONF.151/26/Rev.1 (Vol. 1) (3-14 June 1992), Annex I, pp. 3-8, reprinted in 31 I.L.M. 874 (1992))

Principle 12: States should cooperate to promote a supportive and open international economic system that would lead to economic growth and sustainable development in all countries, to better address the problems of environmental degradation. Trade policy measures for environmental purposes should not constitute a means of arbitrary or unjustifiable discrimination or a disguised restriction on international trade. Unilateral actions to deal with environmental challenges outside the jurisdiction of the importing country should be avoided. Environmental measures. addressing transboundary or global environmental problems should, as far as possible, be based on an international consensus.

Prinsip 12 pada Konvensi Rio de Janeiro 1992 spesifik mengatur bagaimana peran negara peserta untuk kooperatif dalam mempromosikan sistem ekonomi internasional yang terbuka, di mana pertumbuhan ekonomi tersebut beriringan dengan dijalankannya prinsip pembangunan berkelanjutan bagi para pihak. Kebijakan perdagangan dari semua nejgara diharapkan mampu mengantisipasi persoalan degtadasi lingkungan yang terjadi akibat aktivitas perdagangan 
internasional, di mana hal tersebut menjadi tantangan di tengah kondisi lingkungan global untuk membuat konsensus bersama.

Berkenaan dengan agenda 21 di Johanesburg yang lebih dikenal dengan Millenium Development Goals (MDGs), membahas tentang perkembangan terbaru mengenai sustainable development di dunia dengan beberapa prinsip yang disepakati di mana prinsip hukum di dalam perdagangan internasional seyogyanya selalu mengedepankan prinsip lingkungan internasional dan pemenuhan HAM dari masyarakat di mana perusahaan itu berada seperti dijelaskan dalam prinsip berikut (La Vina, 2002: 5):

socioeconomic dimensions (e.g., habitats, health, demography, consumption, and production atterns); conservation and resource management (e.g., atmosphere, forest, water, waste, chemical products); strengthening the role of nongovernmental organizations and other social groups, such as trade unions, women, youths; and measures of implementation (e.g., financing, institutions).

Ketentuan-ketentuan mengenai the atmosphere (ch. 9), biological diversity (ch. 15), the oceans (ch. 17), and freshwater resources (ch. 18), as well as discussion of specific problems such as biotechnology (ch. 15), toxic chemicals (ch. 19), and waste (chs. 2022) dibahas secara khusus dalam beberapa bagian-bagian sehingga rekomendasi yang dikeluarkan lebih spesifik dan khusus (La Vina, 2002: 6).

Masyarakat internasional memahami betul, bahwa perkembangan teknologi dan industrialisasi yang sedemikian pesat menimbulkan persoalan baru, yaitu munculnya perubahan iklim yang tidak dapat terduga, bencana alam, hilangnya keanekaragaman hayati, menurunnya jumlah kondisi air yang menjadi masalah yang signifikan berpengaruh bagi kesejahteraan masyarakat, khususnya masyarakat negara berkembang. Maka dari itu, masyarakat internasional pada 2015 melalui sidang Majelis Umum PBB menyepakati "Transforming Our World: the 2030 Agenda for Sustainable Development Goals/ UN 2030 Agenda" yang selanjutnya disebut SDGs (Zhivkova, 2014: 90).

Pada SDGs, PBB menunjuk UN Development Program (UNDP) sebagai leading sector dalam pelaksanaan pembangunan berkelanjutan, terdiri dari 17 tujuan (goals), 169 target, dan 241 indikator yang direncanakan dapat dicapai selama 15 tahun sampai dengan tahun 2030 bagi semua negara peserta, di mana target SDGs tidak hanya persoalan kemiskinan, kelaparan, kesehatan, dan pendidikan yang telah dibahas dalam MDGs. Namun, target SDGs lebih mengarah terhadap area-area lain yang belum diatur pada MDGs, yaitu tentang pertumbuhan ekonomi, perlindungan lingkungan hidup, hingga persoalan perdamaian, keadilan, dan akuntabilitas internasional (John, 2015: 1121).

Keterkaitan SDGs dengan persoalan perdagangan internasional dan HAM, dapat ditemukan dalam beberapa tujuan, semisal di goal ke-7 berkenan dengan akses terjangkau bagi energi berkelanjutan, di mana diharapkan pelaku bisnis dapat 
menghindari sebanyak mungkin penggunaan energi tidak terbarukan sebagai basis produksi, termasuk pengurangan gas emisi yang akan menyebabkan polusi dan perubahan iklim secara signifikan (UNDP, 2015: 10). Kemudian, pada goal ke-8, berkenaan dengan akses kerja dan pertumbuhan ekonomi, diharapkan mampu melahirkan kesempatan kerja yang diberikan oleh korporasi transnasional terhadap masyarakat host country secara terbuka dan non-diskriminatif (UNDP, 2015: 11). Serta membangun industri berkelanjutan yang mengikuti perkembangan digitalisasi teknologi serta berupaya sebesar-besarnya untuk menghindari eksploitsi sumber daya alam dengan prinsip hemat energi, yang dituangkan dalam goal ke-9 (UNDP, 2015: 12).

Dalam ketentuan-ketentuan perjanjian internasional tersebut norma yang diatur telah cukup jelas dan mewakili aspek-aspek yang dibutuhkan dalam menciptakan kondisi pembangunan yang berkelanjutan sesuai dengan kondisi lingkungan hingga perlindungan kepada kegiatan bisnis yang mengedepankan perlindungan, penghormatan, dan pemulihan atas HAM dari warga negara di mana korporasi multinasional tersebut beroperasi, perlunya komitmen dari negaranegara sebagai bagian dari masyrakat internasional untuk menuangkan prinsipprinsip tersebut pada perundang-undangan dan kebijakan dalam negeri sehingga terjadinya koherensi aturan dalam hukum internasional terhadap prinsip hukum nasional.

Negara diharapkan mempunyai peran andil penting dalam hal menjamin bagaimana efek pelanggaran HAM yang diakibatkan oleh aktivitas perdagangan internasional dapat diminimalisir sedemikian rupa melalui prinsip perlindungan (to protect) dan penghormatan (to respect) HAM warga negara. Sehingga, masyarakat mendapatkan banyak manfaat dari aktivitas perdagangan internasional yang dilakukan oleh negara. serta pembangunan berkelanjutan juga terwujud melalui prinsip memperbaiki (to remedy) bagi korporasi transnasional yang ditemukan telah melakukan kerusakan lingkungan dan disertai pelanggaran HAM dalam aktivitas bisnisnya.

\section{Kasus-Kasus Pelanggaran HAM Akibat Perdagangan Internasional}

\section{a. Efek yang Ditimbulkan dari Perdagangan, Lingkungan dan Penegakkan HAM}

Melalui perjanjian-perjanjian internasional yang diungkap di atas. Sebetulnya, negara-negara di dunia memiliki perhatian dan kesadaran (awareness) kepada penerapan sistem perdagangan juga perhatikan aspek kemanusiaan. Namun demikian, tidak jarang kita temui pelanggaran yang terjadi di beberapa Negara semisal tidak patuhnya korporasi transnasional untuk memperhatikan ketentuanketentuan konvensi internasional.

P.K.Rao membahas mengenai efek yang dihasilkan dari perdagangan internasional menyebabkan sesuatu yang bertolak belakang dengan alasan 
pemenuhan konsumsi dan mendorong pertumbuhan ekonomi melalui kegiatan ekspor dan impor secara besar-besaran dan menciptakan liberalisasi pasar. Ini menyebabkan para pelaku usaha melakukan segala cara, salah satunya dengan melanggar ketentuan-ketentuan dari hal-hal yang berkaitan dengan sustainable development dan HAM seperti yang akan dijelaskannya di bawah ini (Rao, 2000: 32):

"In general, trade liberalization leads to greater volume of export-import activities, enhancing economic growth and consumption. Both the production and consumption processes affected by trade liberalization tend to lead to greater pollution on a per capita basis. This is not necessarily undesirable in most economies. However, uncontrolled emissions of pollutants and utilization of non-renewable resources can lead to a series of problems. These problems are typically uncompensated externalities of pollution, like low quality of air at local levels, and greenhouse gas emissions affecting the global problems. In principle, augmented income levels, technological progress and capacities to handle growing environmental problems in this process enable countries and economic entities to cope with offsetting measures"

Hal tersebut menjadi persoalan yang terjadi di dalam sistem perdagangan internasional yang kemudian menimbulkan ambivalensi. Sementara di sisi lain pertumbuhan ekonomi menjadi "godaan" bagi negara-negara untuk melakukan perdagangan bebas secara all out. Tidak hanya itu, kemajuan teknologi muncul persoalan global dan berbagai macam efek destruktif yang ditimbulkan dalam kegiatan perdagangan internasional yang dilakukan oleh korporasi transnasional. Dalam hal ini, negara diharapkan mempunyai peran andil penting dalam hal menjamin agar persoalan tersebut dapat diminimalisir melalui kebijakan nasional dengan melihat instrumen-instrumen hukum internasional, sehingga masyarakat tidak terlanggar hak-hak asasinya.

\section{b. Kasus Pelanggaran HAM dan Pembangunan Berkelanjutan dalam Perdagangan Internasional}

1) In re Amoco Cadiz Case (in re Amoco Cadiz 659 F.2nd 789 (7th cr))

Praktik-praktik menangani kasus-kasus korporasi internasional yang melanggar prinsip pembangunan berkelanjutan dengan kaitannya masalah pencemaran lingkungan, seperti kasus In re Amoco Cadiz case (Prihandono dan Khairunisa, 2016: 41-42). Pada kasus tersebut US District Court for the Northern District of Illinois, Eastern Division memberikan vonis pertanggungjawaban hukum kepada dua anak perusahaan korporasi transnasional di bidang pertambangan minyak, Amoco Cadiz yang beroperasi di perairan Prancis karena tumpahan cairan oli dari kapal laut milik perusahaan milik Amoco Cadiz Standard Oil Company (SOC) yang merupakan induk perusahaan dari dua anak perusahaan yang beroperasi di perairan prancis yaitu Amoco International Oil Company (AIOC) serta Amoco Transport Company (ATC) sebagai pemilik kapal (Gundlacht E.R, 1989: 503-504). 
Pengadilan memutuskan AIOC sebagai anak perusahaan telah melanggar prinsip kehati-hatian dalam beberapa hal, yaitu: 1) Kewajiban AIOC untuk memastikan awak kapal merupakan buruh terampil yang dapat menjalankan dan mengoperasikan kapal, termasuk meminimalisir dampak resiko yang akan mungkin terjadi; 2) Spesifikasi kapal yang dibangun untuk berlayar juga seharusnya sudah dipastikan oleh perusahaan tersebut sehingga perusahaan memperbolehkan izin berlayar; 3) Kelengkapan dokumen-dokumen kapal yang memadai bila kapal tersebut mengalami kejadian seperti kasus ini tidak ada, sehingga kasus tersebut dianggap sebagai suatu unsur kesengajaan (Gundlacht E.R, 1989: 505-506).

Dari bukti yang ditemukan tersebut, perusahaan AOIC dan ATC sebagai bagian dari konsorsium perusahaan SOC dan pemegang saham mayoritas wajib bertanggungjawab dan menjalakan hukuman yaitu, direct liability. SOC sebagai induk bertanggungjawab melakukan pemulihan atas perairan Perancis yang tercemar oli tersebut agar kemudian kadar air kembali seperti normal, karena perairan tersebut dimanfaatkan oleh nelayan untuk kegiatan penangkapan ikan yang menyuplai kebutuhan ikan masyarakat Prancis, kedua melalui derreivative liability, bahwa kemudian AOIC dan ATC wajib dikontrol penuh dalam kaitannya mematuhi sistem dan aturan hukum yang ditetapkan mengenai pengangkutan minyak oleh SOC dalam operasi kerja setelahnya (Gundlacht E.R, 1989: 507-508).

2) Pembakaran Hutan PT. Jatim Jaya Perkasa

Kasus ini didaftarkan pada 15 Juli 2013 melalui Roundtable on Sustainable pal$m$ Oil (RSPO) yang dilakukan oleh RSPO ExecutiveBoard (https://rspo.org/members Lcomplaints/status-of-complaints/view/35, akses 30 Januari 2018). Pelanggaran yang dilakukan oleh perusahan tersbut yaitu melakukan pembakaran hutan secara terbuka di Riau untuk mengalihfungsikan dari hutan gambut ke hutan produksi kelapa sawit. Dampak yang ditimbulkan menyebabkan asap mencemari wilayah udara di semenanjung Malaysia dan Singapura dan menyatakan paparan pencemarannya termasuk kategori berbahaya. PT Jatim Jaya Perkasa dikomplain atas pelanggaran prinsip nomor 5 RSPO tentang pertanggungjawaban lingkungan dan konservasi lingkungan hidup dan keanekaragaman hayati.

RSPO merupakan bentuk komplain dari munculnya konflik atau sengketa antar stake holder yang membutuhkan solusi dan difasilitasi oleh para pihak yang berkepentingan, khususnya pada kasus perkebunanan kelapa sawit secara nonlitigasi. Dalam keputusannya, RSPO menyatakan perusahaan PT. Jatim Jaya Perkasa melanggar ketentuan pada Prinsip 5 dan menyatakan wajib bertanggungjawab atas kasus tersebut, hingga pembenahan melalui pengadaan patroli uuntuk mengawasi titik api yang akan berpotensi muncul, meningkatkan pengelolaan air, dan membuat laporan berkala.

Atas peristiwa kebakaran Kebakaran lahan seluas 1.000 hektar lahan gambut di areal PT Jatim Jaya Perkasa, aparat penegak hukum telah memproses pihak PT 
Jatim Jaya Perkasa secara Pidana. Selanjutnya pada 23 Maret 2015, Kementerian Lingkungan Hidup dan Kehutanan Republik Indonesia KLHK (KLHK RI) didesak oleh koalisi masyarakat anti mafia hutan menggugat perusahaan itu d PN Jakarta Utara dengan nomor perkara 32/Pdt.G/2015/PN.JKT.UTR. KLHK RI menggugat PT Jatim Jaya Perkasa agar mengganti biaya pemulihan lingkungan terhadap lahan yang terbakar seluas 1.000 hektare senilai Rp371 miliar, serta biaya ganti rugi materiil senilai Rp 199 miliar (http://www.greeners.co/berita/koalisi-anti-mafia-hutanminta-pt-jatim-jaya-perkasa-membayar-ganti-rugi-karhutla/, akses 30 Januari 2018).

3) Elsam et al vs PT. Holcim Indonesia

Non-Governmental Organization (NGO) Indonesia dan Swiss mengajukan komplain pada NCP OECD di Swiss terhadap PT Holcim Indonesia yang merupakan Holcim Ltd. Group, korporasi multinasional yang berkedudukan di Swiss sebagai home country yang bergerak di bidang semen, agregat, beton, aspal. Pengadu menyatakan Holcim Indonesia melanggar beberapa ketentuan OECD Guideline dengan memberikan lahan kompensasi yang tidak sesuai bagi masyarakat Desa Ringinharjo, Kabupaten Tuban, Provinsi Jawa Timur, Indonesia, yang kemudian menyebabkan kekeringan air untuk kepentingan irigasi persawahan khususnya bagi pendirian pabrik semen Holcim di sekitar area tersebut (https://www.oecdwatch.or $\mathrm{g} /$ cases/Case 356, akses 31 Januari 2018).

Pada kasus yang didaftarkan 19 Maret 2015 tersebut, bagi pihak pengadu menyatakan, Holcim Indonesia tidak melakukan uji tuntas HAM dan tidak berkonsultasi kepada masyarakat yang berada disekitar kegiatan produksi semen tersebut. Pengadu meminta NCP OECD di Swiss untuk kesepakatan perlindunganhak-hak masyarakat terdampak dari produksi semen Holcim Indonesia di Tuban dan memfasilitasi dialog lebih lanjut, agar dampak kerusakan alam dan kerugian yang dialami oleh masyarakat tidak semakin parah di kemudian hari. (Prihandono dan Khairunnisa, 2016: 120-121)

Pada kasus-kasus yang telah disajikan telah membuktikan bahwa korporasi transnasional secara langsung melakukan pelanggaran HAM dan perusakan lingkungan, hingga ancaman (threat) terhadap proses kedaulatan negara. Persoalan ini perlu diatasi dalam penegakkan mekanisme hukum internasional, di mana dalam putusan pengadilan ekstrateritorial tersebut sukar bagi penggugat yang merupakan korban mendapatkan keadilan dan pertanggungjawaban atas pelanggaran HAM dan kerusakan lingkungan yang ditimbulkan.

\section{KESIMPULAN}

Negara diharapkan mempunyai peran andil penting dalam hal menjamin bagaimana efek pelanggaran HAM yang diakibatkan oleh aktivitas perdagangan internasional dapat diminimalisir sedemikian rupa melalui prinsip perlindungan (to protect), dan penghormatan (to respect) HAM warga negara. Sehingga, masyarakat 
mendapatkan banyak manfaat dari aktivitas perdagangan internasional yang dilakukan oleh negara. serta pembangunan berkelanjutan juga terwujud melalui prinsip memperbaiki (to remedy) bagi korporasi transnasional yang ditemukan telah melakukan kerusakan lingkungan dan disertai pelanggaran HAM dalam aktivitas bisnisnya.

Pada kasus-kasus yang telah disajikan telah membuktikan bahwa korporasi transnasional secara langsung melakukan pelanggaran HAM dan perusakan lingkungan, hingga ancaman (threat) terhadap proses kedaulatan negara. Persoalan ini perlu diatasi dalam penegakkan mekanisme hukum internasional. Pada putusan pengadilan ekstrateritorial tersebut, sukar bagi penggugat yang merupakan korban mendapatkan keadilan dan pertanggungjawaban atas pelanggaran HAM dan kerusakan lingkungan yang ditimbulkan.

\section{DAFTAR PUSTAKA}

\section{a. Buku}

Chioma, Filomina (2009). Environmental Justice in New Millenium: global perspectives on race, ethnicity, and human right. Bassingstone: Palgrave Macmilan.

Francioni, Fransesco (2001). Environment, Human Right, and International Trade. Oxford-Portland Oregon: Hart Publishing.

K. Anton, Donald dan L- Shelton, Dinah (2011). Environmental Protection \& Human Right. New York: Cambridge University Press.

Lee, Eun Sup (2012). World Trade Regulation: International Trade Under The WTO Mechanism. New York: Springer.

Marzuki, Peter Mahmud (2005). Penelitian Hukum. Jakarta: Kencana Prenada Group.

Matsushita, Mitsuo et.al, (2006). The World Trade Organization; law, practice, and policy. Oxford University Press: New York.

Pelaez, Ana Gonzalez (2005). Human Rights and World Trade: Hunger in International Society. New York: Routledge.

Prihandono, Iman dan Khairunisa, Andi (2016). Tanggung Jawab Korporasi dalam Hukum HAM Internasional. Surabaya: Airlangga University Press.

Rao, P.K. (2000). The World Trade Organization and Environment. Bassingstoke: Palgrave Macmilan.

UNDP (2015). Sustainable Development Goals Booklet. New York: UNDP.

WTO (2015). Understanding the WTO. Geneva: WTO Publisher.

\section{b. Jurnal dan Prosiding}

Fasterling, Björn and Demuijnck, Geert (2013). Human Rights in the Void? Due Diligence in the UN Guding Principles on Business and Human Rights. Journal Business Ethics: JBE, 116(4).

Gundlach, E. R. (1989). Amoco Cadiz Litigation: Summary of the 1988 Court Decision. Proceedings of the 1989 Oil Spill Conference, Washington, D.C., American Petroleum Institute. 
Maurice, John (2015). The Lancet. London, 386(9999).

Schumacher, Reinhard (2012). Adam Smith's theory of absolute advantage and the use of doxography in the history of economics. Erasmus Journal for Philosophy and Economics, 5(2).

Zhivkova, Stela (2014). International Conference On Innovation, Technology Transfer And Education February 3-5, 2.

\section{c. Regulasi, Putusan, Working Paper}

Antonio G.M. La Vina, Gretchen Hoff, Anne Marie DeRose, (2002), The Successes and Failures of Johannesburg: a Story of Many Summits: a Report on the World Summit on Sustainable Development for Donors and Civil Society Organization, World Resource Institute, Washington D.C

Beanal vs Freeport MacMoran, Inc Case (9969 F.Supp. 362: 373)

In re Amoco Cadiz Case (in re Amoco Cadiz 659 F.2nd 789 (7th cr))

John Doe I, et al v Exxon Mobil Coorporation Case (393 E.Supp. 2d 20: 25)

Marrakesh Agreement Establishing the World Trade Organization, signing 1994 at Uruguay Round

Norms on the Responsibilities of Transnational Corporations and Other Business Enterprises with Regard to Human Rights. (U.N. Doc. E/CN.4/Sub.2/2003/12/Rev.2 (2003)).

The Rio Declaration on Environment and Development, Report of the United Nations Conference on Environment and Development A/CONF.151/26/Rev.1 (Vol. 1) (3-14 June 1992), Annex I, pp. 3-8, reprinted in 31 I.L.M. 874 (1992)

UN Office of the High Commision for Human Right, (2014). The UN Guiding Principles on Business and Human Rights: Relatioship to UN Global Compact Commitment, New York (U.N. Doc. E/CN.4/Sub.2/2003/12/Rev.2 (2003)).

\section{d. Internet}

http://www.businessdictionary.com/definition/international-trade.html, akses Januari 2018

http://www.greeners.co/berita/koalisi-anti-mafia-hutan-minta-pt-jatim-jayaperkasa-membayar-ganti-rugi-karhutla/ , akses 30 Januari 2018

http://www.ohchr.org/EN/Issues/Pages/WhatareHumanRights.aspx, diakses pada 1 Januari 2018

http://www.unisosdem.org/article detail.php?aid=6343\&coid=1\&caid=56\&gid=3. akses pada 24 Januari 2018

https://business-humanrights.org/en/united-nations-sub-commission-norms-onbusiness-human-rights-explanatory-materials , akses pada 10 Januari 2018

https://law.justia.com/cases/federal/district-courts/FSupp/969/362/1808395/, akses 28 Januari 2018

https://rspo.org/members/complaints/status-of-complaints/view/35, akses 30 Januari 2018 